\title{
Intervenciones disruptivas al comienzo de la vida humana: un debate bioético y del bioderecho sobre la "pena de muerte" prenatal
}

\author{
Amparo de Jesús Zárate Cuello ${ }^{1}$, \\ Yolanda Guerra García ${ }^{2}$, Joao Cuesta ${ }^{3}$
}

Amparo de Jesús Zárate Cuello PhD. Abogada de la Universidad Libre de Colombia. Docente Investigadora U. Militar Nueva Granada,

Doctora en Derecho, Departamento Filosofía del Derecho.

2. Yolanda M. Guerra. Post PhD. Docente Investigador Post Doctora en Investigación, Post Doctora en Narrativa en Ciencia, Post Doctora en Comunicación,

Educación y Cultura, Facultad de Educación y Humanidades.

Directora del grupo de investigación Liderazgo. Universidad Militar Nueva Granada.

3. Joao Cuesta Mg. Biólogo. M Sc. Enseñanza de las Ciencias Universidad Pontificia. Javeriana, Docente Investigador, Director de Postgrados, Facultad de Educación y Humanidades.

Correspondencia: yolanda.guerra@unimilitar.edu.co

Recibido: 23/05/2013 Aceptado: 07/07/2013

\section{Resumen}

La intervención disruptiva que más genera debate sobre la "pena de muerte prenatal", desde la perspectiva de la bioética y el bioderecho, es sin duda el aborto. En este caso se trata de acabar deliberadamente con la vida: prima facie, la del hijo no deseado. Elucidaremos sobre la dignidad del ser humano, desde el momento mismo de la concepción de la persona humana, en acopio al derecho a la protección de la vida física del que está por nacer.

La despenalización del aborto conlleva a la "pena de muerte" al comienzo de la vida humana, con connotaciones bioéticas, biomédicas, biopolíticas y del bioderecho. Permeando a las futuras generaciones con el postulado del principio de autonomía y el consentimiento informado que entrama el determinismo biológico de quienes deben morir, se examina la "pena de muerte prenatal" ante el aborto en España y Colombia.

Palabras clave: aborto, bioética, bioderecho, biopolítica, consentimiento informado, pena de muerte prenatal. 


\title{
Disruptive interventions at the beginning of human life: a bioethical and biolaw debate on the prenatal "death penalty"
}

\begin{abstract}
Abortion is undoubtedly the disruptive intervention that generates the most debate on the "prenatal death penalty" from the perspective of bioethics and BioLaw. In this case, it is about the deliberate ending of life: prima facie, that of the unwanted child. We will talk about the dignity of the human being, from the moment of the conception of the human person, in the invoking the right to the protection of the physical life that is about to be born.
\end{abstract}

The decriminalization of abortion leads to the "death penalty" at the beginning of human life, with bioethical, biomedical, biopolitical and BioLaw connotations. Permeating future generations with the postulate of the principle of autonomy and informed consent which links the biological determinism of those who must die, we will discuss the "prenatal death penalty" against abortion in Spain and Colombia.

Key Words: abortion, bioethics, biolaw, biopolitics, informed consent, prenatal death penalty.

\section{Introducción}

¿Cuál es el momento en el que comenzamos a vivir?, será ese momento en que interrumpimos el silencio dentro del cuerpo de nuestra progenitora, o será el preciso instante en el cual la unión de dos gametos desata un sinfín de procesos biológicos y químicos que permiten la división celular de un cigoto, en dos, cuatro, ocho, dieciséis unidades y así sucesivamente conformando lo que a las pocos días se conoce como mórula. Si todo va bien dentro del proceso natural y no hay intervenciones externas como el aborto, que impidan el desarrollo normal de un embrión o feto, se dará lugar a una persona que al nacer tendrá los atributos de la personalidad jurídica que le otorga la ley, el derecho humano y fundamental de construir su proyecto de vida digna como miembro de la especie humana; debidamente reconocido, amparado en los tratados internacionales y en el derecho interno de los Estados, que en su gran mayoría garantizan el derecho a la vida y proscriben la pena de muerte. Sin embargo, se evidencia en el siglo XXI una transgresión a este derecho humano fundamental como lo es el "derecho a la vida" al despenalizarse el aborto con legislación de plazos como es el caso paradigmático de España y en tres situaciones especiales, como lo plantea la biojurisprudencia de la Corte Constitucional Colombiana.

Este asunto, materia de debate dentro del discurso dialógico de la bioética y del bioderecho, admite que se susciten cuestiones ante los avatares de las biopolíticas, en el auge de la globalización, que se dirigen a indagar sobre ¿cuándo debe finalizar está vida? ¿Cuándo es lícito intervenir para interrumpir el curso natural de nacer? ¿De qué forma y en qué circunstancias es éticamente permisible truncar la existencia humana? ¿Puede considerarse cualquier acción de intervención sobre el continuum biológico de la vida como una pena de muerte? (1).

Estos tópicos presentan un contraste entre los argumentos filosóficos de la bioética personalista y el utilitarismo sobre la cultura de la vida y de la muerte, donde los principios bioéticos de 
beneficencia, autonomía, justicia y no maleficencia varían ostensiblemente, principalmente por la situación que atañe a la distribución de recursos sanitarios, lo cual origina necesidades que no se logran satisfacer de un modo justo y equilibrado. Por tal motivo cada vez los usuarios de los sistemas de salud son más autónomos y autogestionan su vida, su cuerpo, su sexualidad y hasta su muerte (2).

\section{Pena de muerte al comienzo de la vida: el aborto}

Sin duda alguna la "pena de muerte", representada en el aborto, es la violación más ostensible sobre el derecho a la vida. La pena de "muerte prenatal" es la disrupción de la vida cuando empieza a desarrollarse en el seno de la madre un nuevo ser humano: impidiéndose así su continuum de orden biológico, embriológico, ontológico y de su ciclo vital como persona única e irrepetible.

En principio, en el caso que nos ocupa, cuando se produce la interrupción voluntaria del embarazo, lo que plantea problemas éticos, en virtud que es producido con el concurso de la voluntad que implica la responsabilidad del sujeto (3). Vale decir, que también presentan cuestionamientos indudablemente bioéticos, que forzosamente permiten reflexionar al bioderecho. Es así como, estudiando el tema de la pena de muerte prenatal con ocasión del aborto, en dos países distintos como lo son España y Colombia, se puede observar desde la perspectiva de las Cartas Magnas en sendos ordenamientos jurídicos.

Por una parte, para Colombia, el Articulo 11 de la Constitución Política de 1991, establece que "El derecho a la vida es inviolable no habrá pena de muerte". Asimismo, la Constitución Española señala en el Art. 15 "Todos tienen derecho a la vida y a la integridad física y moral, sin que, en ningún caso, puedan ser sometidos a tortura ni a penas o tratos inhumanos o degradantes. Queda abolida la pena de muerte, salvo lo que puedan disponer las leyes penales militares para tiempos de guerra”. Empero, tal como está concebido este Derecho Fundamental en las referidas constituciones, podría a grandes rasgos colegirse que el derecho supremo de la vida, es conferido a cada ser humano desde el momento de la concepción. Pero este Derecho Fundamental no ha sido interpretado de tal suerte al tenor de la biojurisprudencia.

\section{Aborto caso Colombia}

Para Colombia, la Corte Constitucional en la Sentencia C-355 del 2006 estipuló:

"Se declarará por lo tanto ajustado a la Constitución el artículo 122 del Código Penal en el entendido que no se incurre en delito de aborto, cuando con la voluntad de la mujer, la interrupción del embarazo se produzca en los siguientes casos: a) Cuando la continuación del embarazo constituya peligro para la vida o la salud de la mujer, certificado por un médico; b) cuando exista grave malformación del feto que haga inviable su vida, certificada por un médico; c) cuando el embarazo sea resultado de una conducta, debidamente denunciada, constitutiva de acceso carnal o acto sexual sin consentimiento, abusivo, o de inseminación artificial o de transferencia de óvulo fecundado no consentidas, o de incesto". Corte Constitucional Sentencia C-355 del 2006.

Cabe destacar que la Corte Constitucional discernió claramente sobre la diferencia existente entre la vida como un bien constitucionalmente protegido y el derecho a la vida como un derecho subjetivo de carácter fundamental: planteando que la protección a la vida, en su carácter de bien goza de relevancia constitucional y vincula a todos los poderes públicos y a todas las autoridades estatales colombianas, y corresponde al Congreso adoptar las medidas idóneas para cumplir con el deber de protección de la vida, lo cual no significa que estén justificadas todas las que dicte con dicha finalidad, porque a pesar de su relevancia constitucional la vida no tiene la condición de valor o derecho de carácter absoluto, debiendo ser ponderado con otros valores, principios y derechos constitucionales. Corte Constitucional Sentencia C-355 del 2006. 
En este contexto la Corte Constitucional se pronuncia en los siguientes términos:

"...la vida y el derecho a la vida son fenómenos diferentes. La vida humana transcurre en distintas etapas y se manifiesta de diferentes formas, las que a su vez tienen una protección juridica distinta. El ordenamiento juridico, si bien es verdad, que otorga protección al nasciturus, no la otorga en el mismo grado e intensidad que a la persona humana. Tanto es ello asi, que en la mayor parte de las legislaciones es mayor la sanción penal para el infanticidio o el homicidio que para el aborto. Es decir, el bien jurídico tutelado no es idéntico en estos casos y, por ello, la trascendencia jurídica de la ofensa social determina un grado de reproche diferente y una pena proporcionalmente distinta" Corte Constitucional en la Sentencia C-355 del 2006.

Esta sentencia desconoce el carácter de "individualidad del embrión [que] también se ve afectada por la interdependencia con la madre, es decir se cuestiona la personeidad e individualización del embrión, desde dos acercamientos diferentes, uno su autonomía, otro desde el hecho que el embrión no posee la información suficiente para su desarrollo" (4).

Por consiguiente, señala casos excepciones donde se viola la vida y se permite la pena de muerte, a contrario sensu de la disposición constitucional del artículo 11, al no reconocerle al nasciturus su condición de ser humano y al permitir a la mujer y al Estado, a través de las biopolíticas públicas, la decisión de quien debe vivir o morir, proliferándose en Colombia la "pena de muerte prenatal".

Ante estas situaciones fácticas, el gobierno colombiano, representado por el Ministerio de la Protección Social, se pronuncia mediante el Decreto 4444 de 2006 por el cual se reglamenta la prestación de unos servicios de salud sexual y reproductiva, para garantizar el "goce efectivo en condiciones de igualdad y de seguridad dentro del sistema de seguridad social en salud". Es decir, con la disponibilidad de acceso a la interrupción voluntaria del embarazo en todo el territorio nacional para todas las mujeres, independientemente de su capacidad de pago y afiliación al sistema de seguridad social en salud 4. Decreto que se expidió con el propósito de reglamentar la precitada Sentencia C-355/06 sobre la despenalización de los tres casos citados correspondientes al aborto en Colombia, en el sentido de "garantizar la prestación del servicio público esencial de salud, evitar barreras de acceso y no vulnerar los derechos fundamentales protegidos por la Sentencia C-355/06, [asimismo determinando que] la objeción de conciencia es una decisión individual y no institucional, que aplica exclusivamente a prestadores directos y no a personal administrativo." En tal virtud, "ninguna entidad deberá poner trabas administrativas que posterguen la prestación del servicio, además del establecimiento de las normas técnicas y de financiación para los procedimientos" (5). Con base a esta reglamentación, se realizarían los abortos amparados en la Sentencia de la Corte Constitucional en comento.

Cabe señalar que el Consejo de Estado suspendió, provisionalmente, los efectos jurídicos de este Decreto 4444/06, teniendo en cuenta que esta norma fue demandada en acción pública de nulidad, que se impetró por el desconocimiento del ejercicio de la potestad reglamentaria por parte del gobierno, por no existir ley que regule el aborto a posteriori de la Sentencia C-355 de 2006 de la Corte Constitucional.

Finalmente, mediante fallo de la Sección Primera del Consejo de Estado de fecha 13 de Marzo del 2013, se declara la nulidad del Decreto 4444 del 2006 con los fundamentos jurídicos de carácter constitucional, interpretando que la potestad reglamentaria que consagra el artículo 189, numeral 11 de la Constitución Política de Colombia "no puede ejercerse en abstracto, ni frente a actos jurídicos distintos de las leyes o decretos leyes". En otras palabras, los decretos expedidos por el Gobierno Nacional, en acopio de la potestad reglamentaria, en ningún caso reglamentan las sentencias. 
El efecto de la nulidad deja sin soporte jurídicoadministrativo la financiación del aborto por parte del sistema de seguridad social del Estado, pues no existe disposición legal que reglamente el procedimiento del aborto. Por ende, es imprescindible la intervención del Legislador en cuanto a la regulación de los casos despenalizados "pues pretender que esta práctica sea obligatoria, gratuita, inmediata e incluso que proceda en los 9 meses de embarazo, como en su momento también lo sugirió la Sala Octava de Revisión de la Corte Constitucional (Sentencia T-841 de 2011), aún sin que exista ninguna reglamentación al respecto, es algo que sin duda pone en grave riesgo los derechos a la salud y la vida de las mujeres gestantes, así como los derechos de los profesionales y las instituciones de salud, entre otros" (6).

Estas falencias y vacíos del ordenamiento jurídico están permitiendo la propagación del aborto ilegal, abriendo las puertas al campo con los pseudo-legales, generalizando las situaciones de la intervención voluntaria del embarazo, pretendiendo demostrar que el aborto es un derecho: amparándose en los tres casos despenalizados por la Sentencia C-355 del 2006. Interpretación que desconoce lo declarado en la reciente jurisprudencia de nulidad del Decreto 4444 del 2006, proferida por la Sección Primera del Consejo de Estado. Máxime que "la Sentencia C-355 de 2006 no tuvo por objeto consagrar el derecho al aborto, sino despenalizar tres eventos en los cuales su práctica no es constitutiva de delito".

Por su parte, la Organización Women's Link Worldwide, liderada por la abogada feminista Mónica Roa, expresan que la nulidad del Decreto 4444 del 2006, deja incólume la práctica del aborto en los casos despenalizados, ya que estos están cobijados por la Sentencia C-355/06 (7). Esta interpretación es fehacientemente y a todas luces jurídicamente inadecuada, teniendo en cuenta que el "Decreto anulado, su Norma Técnica y los diferentes actos administrativos que se han proferido con fundamento en esta normativa, así como los que han sido amparados o se han ordenado proferir en las sentencias de revisión de la Corte, son prueba de que con la sola sentencia C-355 de 2006 no es suficiente" (6).

Precisamente, por esa razón el gobierno se apresuró a reglamentar lo irreglamentable, pretendiendo legalizar el procedimiento de la práctica del aborto con la profilaxis adecuada. Pero la normativa no tiene vigencia, y la vida del nasciturus se en ruta en la pendiente resbaladiza de la "pena de muerte prenatal" con la autonomía y el consentimiento informado de la madre. Lo cual se establece al revisar las estadísticas del aborto en Colombia.

En un polémico estudio del año 2011 realizado por el Guttmacher Institute y la Fundación Oriéntame, se estima que el $44 \%$ de los embarazos no planeados en Colombia terminan en un aborto inducido. Esto se traduce en unos 400,400 abortos inducidos cada ańo (Tabla 1) (8).

Tabla 1. Según este informe de 89 embarazos no planeados por cada 1,000 mujeres en edad reproductiva, 39 terminan en aborto.

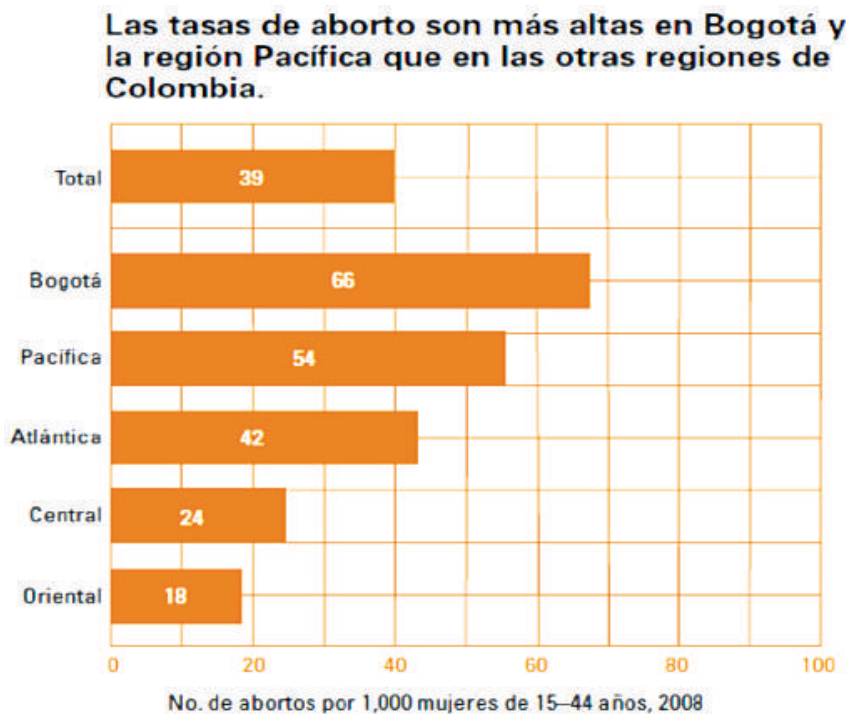

Aun así, y aunque la cifra es alarmante, se queda corta ante lo dicho por la coordinadora de la Red de Bioética de la Universidad Nacional, Carmen Alicia Cardoso quien afirma: "Uno de los graves 
problemas que tiene el aborto en Colombia es el subregistro, eso hace que no tengamos datos exactos, pero de acuerdo a análisis estadisticos en cada una de las regiones, se ha evidenciado que en Colombia se estén produciendo anualmente entre tres y cuatro millones de abortos" (10).

En concordancia con lo anterior, en la Encuesta $\mathrm{Na}$ cional de Demografía y Salud 2010 de Profamilia, encontramos que menos de la mitad de los nacimientos (48 por ciento), ocurridos en los últimos cinco ańos, fueron deseados en ese momento. El 29 por ciento de ellos fueron deseados, pero más tarde, sólo el 23 por ciento fueron reportados abiertamente como no deseados. Además presenta estadísticas porcentuales sobre causales de terminación del embarazo (Tabla 2) (11).

Tabla 2. Distribución porcentual de mujeres alguna vez embarazadas, por características seleccionadas.

\begin{tabular}{|c|c|c|c|c|c|c|c|}
\hline Caracteristica & Pérdida & $\begin{array}{l}\text { Interrupción/ } \\
\text { aborto }\end{array}$ & $\begin{array}{l}\text { Embarazo } \\
\text { extrauterino } \\
\text { (MOLA) }\end{array}$ & $\begin{array}{c}\text { Muerte } \\
\text { fetal } \\
\text { intrauterina }\end{array}$ & Normal & Total & $\begin{array}{l}\text { Número de } \\
\text { mujeres } \\
\text { alguna vez } \\
\text { embarazadas }\end{array}$ \\
\hline $\begin{array}{l}\text { Grupos de edad } \\
1519 \\
20-34 \\
35-39\end{array}$ & $\begin{array}{r}9.9 \\
15.2 \\
17.1\end{array}$ & $\begin{array}{l}6.2 \\
7.6 \\
8.0\end{array}$ & $\begin{array}{l}0.9 \\
1.7 \\
2.4\end{array}$ & $\begin{array}{l}0.9 \\
1.6 \\
2.5\end{array}$ & $\begin{array}{l}82.2 \\
73.9 \\
69.9\end{array}$ & $\begin{array}{l}1000 \\
100.0 \\
100.0\end{array}$ & $\begin{array}{r}1,614 \\
16,052 \\
17,721\end{array}$ \\
\hline $\begin{array}{l}\text { Zona } \\
\text { Urbana } \\
\text { Rural }\end{array}$ & $\begin{array}{l}16.9 \\
12.6\end{array}$ & $\begin{array}{l}7.9 \\
7.0\end{array}$ & $\begin{array}{l}2.3 \\
1.3\end{array}$ & $\begin{array}{l}1.9 \\
2.3\end{array}$ & $\begin{array}{l}70.9 \\
76.9\end{array}$ & $\begin{array}{l}1000 \\
100.0\end{array}$ & $\begin{array}{r}27,273 \\
8,115\end{array}$ \\
\hline $\begin{array}{l}\text { Estadlo conyugal } \\
\text { Soltera } \\
\text { Alguna vez unida } \\
\text { Actualmente unida }\end{array}$ & $\begin{array}{l}12.7 \\
16.8 \\
16.1\end{array}$ & $\begin{array}{l}8.3 \\
8.4 \\
7.4\end{array}$ & $\begin{array}{l}1.7 \\
2.0 \\
2.1\end{array}$ & $\begin{array}{l}0.9 \\
2.1 \\
2.1\end{array}$ & $\begin{array}{l}76.4 \\
70.6 \\
72.2\end{array}$ & $\begin{array}{l}1000 \\
100.0 \\
100.0\end{array}$ & $\begin{array}{r}3,414 \\
7,452 \\
24,521\end{array}$ \\
\hline $\begin{array}{l}\text { Nivel de educación } \\
\text { Ninguno } \\
\text { Primaria } \\
\text { Secundaria } \\
\text { Superior }\end{array}$ & $\begin{array}{l}14.9 \\
14.2 \\
16.7 \\
16.5\end{array}$ & $\begin{array}{l}8.9 \\
7.3 \\
7.6 \\
9.0\end{array}$ & $\begin{array}{l}1.0 \\
1.7 \\
2.2 \\
2.5\end{array}$ & $\begin{array}{l}3.0 \\
2.5 \\
1.8 \\
1.7\end{array}$ & $\begin{array}{l}72.3 \\
74.3 \\
71.7 \\
70.4\end{array}$ & $\begin{array}{l}100.0 \\
100.0 \\
100.0 \\
1000\end{array}$ & $\begin{array}{r}802 \\
10.190 \\
20.827 \\
3,569\end{array}$ \\
\hline $\begin{array}{l}\text { Fecha terminación último emb } \\
\text { que no terminó normalmente } \\
\mathrm{Si} \text {, después de Mayo } 2006 \\
\mathrm{Si} \text {, antes de Mayo } 2006 \\
\text { No sabe/no respuesta }\end{array}$ & $\begin{array}{l}590 \\
57.1 \\
50.2\end{array}$ & $\begin{array}{l}28.0 \\
27.4 \\
44.2\end{array}$ & $\begin{array}{l}7.6 \\
7.4 \\
3.4\end{array}$ & $\begin{array}{l}5.5 \\
8.1 \\
2.2\end{array}$ & $\begin{array}{l}\text { na } \\
\text { na } \\
\text { na }\end{array}$ & $\begin{array}{l}1000 \\
100.0 \\
100.0\end{array}$ & $\begin{array}{r}2.644 \\
6,984 \\
173\end{array}$ \\
\hline Total & 159 & 7.7 & 2.1 & 20 & 72.3 & 1000 & 35.387 \\
\hline
\end{tabular}

Como se observa, existen notables diferencias porcentuales en cuanto a las estadísticas de interrupción voluntaria del embarazo se refiere, evidenciándose la necesidad de un tamizaje que otorgue cifras claras y le dé certeza a la opinión pública y a las instituciones que conforman la estructura del Estado acerca de la realidad de las prácticas del aborto en Colombia tanto legales como clandestinas; teniendo en cuenta que de acuerdo a estadísticas del 2008, la OMS estima que a nivel mundial 358.000 mujeres mueren cada año por causas relacionadas con el embarazo y el parto y entre las causas se encuentra el aborto inseguro.

\section{Aborto caso España}

Ahora bien, en Espańa el reconocimiento del derecho a la vida, debe entenderse para todos los seres humanos, como explícitamente lo consagra el mencionado Artículo 15 en la sección primera "De los derechos fundamentales y de las libertades públicas". Por tanto, "es un principio constitucional surgido de la experiencia de las violaciones de dicho derecho a lo largo del siglo XX" (12). Sin embargo, en la sentencia 53 de 1985 proferida por el Tribunal Constitucional Español, la argumentación sobre el derecho a la vida del nasciturus "parte dentro de la existencia de vida protegible 
pero se debate entre una genérica protección a la vida y la afirmación de que el no nacido, distinto de la madre y que tiene vida humana, que "es una realidad desde el momento de la gestación”, no es considerado como persona ni, en consecuencia, titular de derecho alguno y tampoco del derecho fundamental a la vida.

Se hace una confusa referencia al "momento a partir del cual el "nasciturus" es ya susceptible de vida independiente de la madre, esto es, de adquirir plena individualidad humana”» (13). Es decir, que el mencionado Tribunal considera decisivo que "la vida del nasciturus es un bien jurídico constitucionalmente protegido por el articulo 15 de dicha norma fundamental". Aseverando que esa protección, acarrea aspectos de deber, en lo que concierne a la vida del que está por nacer, como lo es la de proteger el continuum de su gestación. "Esta protección que la Constitución dispensa al nasciturus implica para el Estado con carácter general dos obligaciones: La de abstenerse de interrumpir o de obstaculizar el proceso natural de gestación, y la de establecer un sistema legal para la defensa de la vida que suponga una protección efectiva de la misma y que, dado el carácter fundamental de la vida, incluya también, como última garantía, las normas penales. Ello no significa que dicha protección haya de revestir carácter absoluto; pues, como sucede en relación con todos los bienes y derechos constitucionalmente reconocidos, en determinados supuestos puede y aún debe estar sujeta a limitaciones" (13), lo que nos permite analizar que los derechos del nasciturus atinentes a la protección de la vida, no se pueden ponderar con los del libre desarrollo de la personalidad de la madre aunados a otros derechos que le corresponden a la misma. Priorizándose a todas luces el cenit de los "Derechos de la Mujer", que finalmente es quien le otorga el estatus o no al que está por nacer de ser humano si en su libre albedrio decide si vive o muere.
Esta interpretación ha trascendido hasta las Cortes Generales, conformadas por el Congreso de Diputados y el Senado, fundamentando la expedición de la Ley Orgánica 9 de 1985 que despenalizó el aborto en tres supuestos: "el terapéutico, de riesgo físico o psíquico de la mujer embarazada; el criminológico, atinente a la violación y el eugenésico correspondiente a las malformaciones fisicas o taras en el feto" (14).

Actualmente, el bioderecho español para el contexto que nos ocupa, está contenido en la Ley 2/2010 de 3 de marzo "de salud sexual y reproductiva, y de la interrupción voluntaria del embarazo", que en sus artículos 13 y 14 señala la despenalización de la práctica del aborto inducido en el lapso de las primeras 14 semanas del embarazo. Plazo que tendrá en cuenta la mujer para decidir en forma libre e informada sobre la interrupción del embarazo, sin intervención de terceros en su determinación. De igual manera, en su Artículo 15 la Ley establece la posibilidad de interrumpir el embarazo hasta la semana 22, cuando se presentan "graves riesgos para la vida o la salud de la madre o del feto", en dos situaciones: cuando "se detecten anomalías en el feto incompatibles con la vida" o que "se detecte en el feto una enfermedad extremadamente grave e incurable en el momento del diagnóstico y así lo confirme un comité clínico" (15).

La mencionada Ley de plazos, también conocida como Ley Aido, recibe su nombre por el impulso que le diera en su momento la ex ministra de Sanidad Bibiana Aido, quien afirmó que "un feto de 13 semanas es un ser vivo, pero no podemos decir que es un ser humano" (16).

Esta visión deshumaniza al ser humano en sus primeros estadios de formación, tratándolo como cosa. Por consiguiente, se ha puesto al nasciturus 
en una situación de "pena de muerte prenatal" en el país Ibérico, lo cual es evidente al revisar las últimas cifras del Instituto para la Protección de la Familia español, IPFE; el cual, según un informe del 24 de enero del 2013 sitúa a Espańa con 118.359 abortos en 2011, superando a países como Alemania (108.867 en 2011), Italia (109.538 en 2011) o Rumanía (101.915 en 2010), cuando históricamente estos países han tenido muchos más abortos.

Así pues, mientras en el resto de Europa el aborto se usa cada vez menos como método de planificación familiar, en Espańa ocurre lo contrario, configurándose de tal manera en el país con la mayor tasa de crecimiento de casos de aborto de la UE (17).

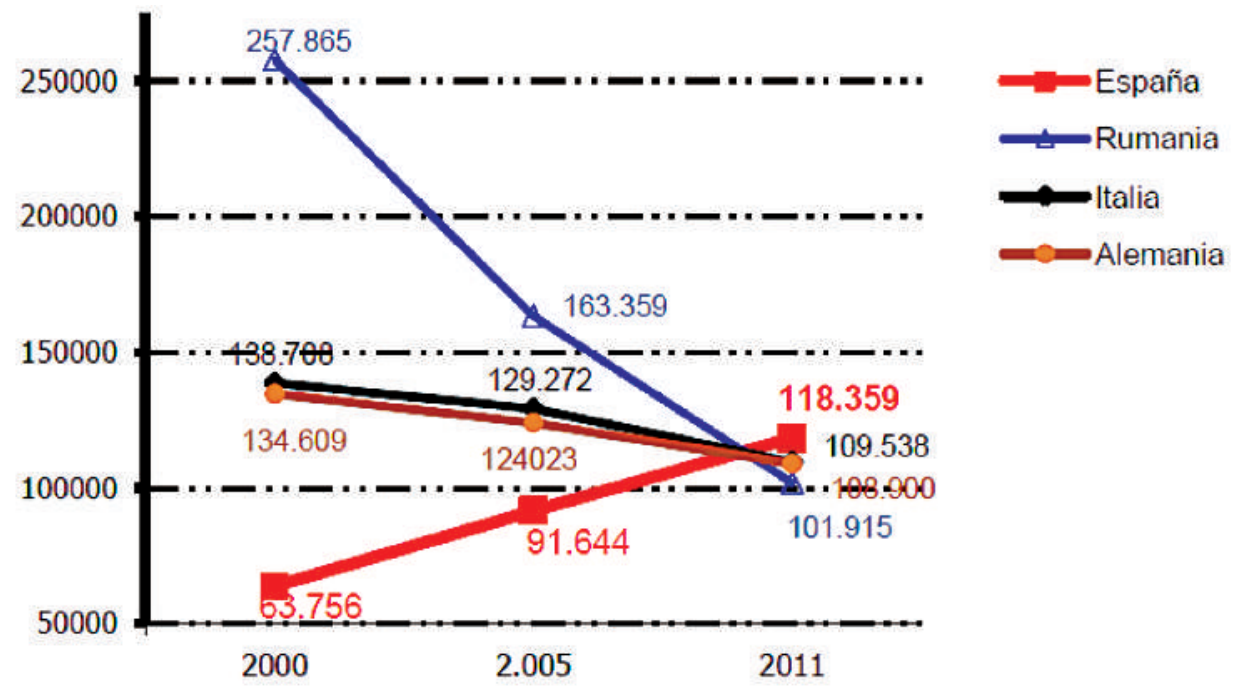

Fuente: Instituto de Politica Familiar (IPF) a partir de datos de Eurostat y fuentes estadisticas nacionales

Ante tan contundentes cifras es pertinente discurrir que el aborto es concebido en Espańa como un derecho, habida consideración a lo sucedido con la reciente sentencia del sonado Caso Morín (18) donde presuntamente en sus clínicas se practicaba el aborto sin límites amparado en la Ley vigente, legitimando por tanto el derecho a asesinar al no nacido en circunstancias diferentes a las contempladas en la Ley de Plazos. No obstante, recientemente el caso Morín ha sido desestimado por falta de acervo probatorio.

Evidenciando la gravedad de la situación actual en Espańa, según lo plantea el Consejo de Estado, "la situación es de aborto libre, al convertirse España en «un paraíso del turismo abortista y el lugar donde más crece el número de abortos en la Unión Europea»" (19). Recientemente, el Gobierno español se ha pronunciado en cuanto a la protección de la vida humana, en el sentido de la voluntad de buscar una legislación que frene la tragedia del aborto, buscando retornar a la Ley de supuestos del ańo 85 . Por su parte entre los grupos pro-vida están desarrollando una campaña denominada Aborto Cero, buscando la eliminación de la práctica en el país, y a su vez las feministas alegan el principio de "no regresividad" (20) ante los derechos que consideran adquiridos por la mujer en cuanto a su libertad reproductiva. Entretanto, "la muerte prenatal" campea dominando la cultura de la muerte en la península ibérica.

\section{Conclusiones}

Inexorablemente, se evidencia en el análisis de legislación comparada entre España y Colombia, cómo el comienzo de la vida del nasciturus se 
encuentra en vilo y se encauza progresivamente hacia la "pena de muerte prenatal". La cultura pro-choice, poco a poco ha ido inmiscuyéndose en el ámbito familiar, atentando contra esta institución, que a lo largo de la historia ha sido soporte de la sociedad, preservando los valores constitutivos de la integralidad del ser humano.

En el contexto de las transformaciones sociales y culturales, la mujer reclama, amparada en el principio fundamental del derecho a la libertad, a su cuerpo y al libre desarrollo de la personalidad, en la pretendida búsqueda de la igualdad con el hombre, aniquilar el derecho a la vida del nasciturus, bajo el supuesto de que un embarazo atenta contra su 'proyecto de vida' y por tanto su realización personal. Efectivamente, "los movimientos feministas actuales ya no pugnan por la equiparación salarial, o antes que eso, por el mismo derecho al trabajo.

El movimiento feminista actual tiene el aborto por bandera, algo que defiende no desde la concepción de un Derecho Fundamental, que acaso pudiera derivarse del derecho a la integridad física que reconocen la mayoría de textos constitucionales, sino que lo defienden como un derecho específico y especial para la mujer" (21). Estos cambios paradigmáticos en el imaginario de la mujer sobre la equidad de género, además, se acentúan con la sombra del concepto del control natal, que surge hacia 1789, con el "Ensayo sobre la población" del inglés Thomas Malthus, el cual expone una postura sobre el peligro que supone el crecimiento de la población para el progreso y bienestar de la sociedad. En consonancia, las Conferencias sobre Población de El Cairo en 1994 y consecutivamente Beijing en 1995, en las cuales se promulgan los derechos reproductivos, proclaman con beneplácito la destrucción de la vida que está por nacer, con la práctica del aborto y las formas de anticoncepción como medidas de control natal. Entendidas como: "Una nueva medicina del cuerpo social más que del individuo que consiste en administrar la vida humana como se administra una materia prima; en constituir una nueva moral basada en el nuevo sentido de la vida; en penetrar en la política con el fin de engendrar una sociedad nueva; en destruir la concepción tradicional de la familia" (22), que ante los avatares de la globalización y del determinismo genético, lejos está quedando de ser la célula o núcleo fundamental de la sociedad.

Estas circunstancias que observamos, en el siglo XXI que nos ha correspondido vivenciar en nuestro desarrollo vital, tienen unos antecedentes que precisamente surgen de la búsqueda de los merecidos derechos de la mujer en el marco de la igualdad de oportunidades con el hombre. Lo que no debería instar a propiciar la "muerte prenatal". Pero, los datos historiográficos apuntan a corroborar lo contrario. A este respecto, es preciso señalar que la estadounidense Margaret Sanger, inició en el siglo XX el movimiento del control de la natalidad e influyó en la legislación a favor del aborto, promoviendo además, el surgimiento de clínicas y hospitales dedicados a la prevención de embarazos no deseados. Sanger, creció con la obsesión de liberar a la mujer de la maternidad con el fin de equiparar la igualdad de derechos del hombre. Sus frases más célebres fueron las siguientes: "lo más misericordioso que una familia numerosa puede hacer con uno de sus miembros más pequeños es matarlo". "Más hijos para los capacitados; menos hijos para los incapacitados, ésa es la esencia del control de la natalidad".

Estos antecedentes, han sido estudiados detalladamente y publicados por Ann Farmer en revistas "especializadas [y] trabajos acerca de la intolerancia de cierto feminismo y cierto laborismo en la cuestión del aborto, que lejos de constituirse en un debate de tipo político se [ha ido transformando] en una cuestión de derechos fundamentales o incluso de posición contra o a favor de la mujer". [...] "El aborto debe buena parte de su prestigio a su supuesta motivación humanitaria. Sería la lucha contra el llamado aborto clandestino y sus secuelas en forma de mortalidad femenina lo que justificaría en última instancia la despenalización, e incluso, como ahora vemos en España, la pura 
y simple legalización", [que se ha ido extendiendo con] "la acción de agencias de Naciones Unidas contra la reproducción en los denominados países pobres" (23).

En estos, figura Colombia, que sigue a pasos agigantados estas directrices y las de la legislación española en el tema del aborto, donde el camino a seguir, es la opción de interrumpir un embarazo que no se planeó y que no se desea, como un derecho sexual y reproductivo de la mujer. Es así como el aborto se ha ideado para disolver a la familia y desaparecer al núcleo de la sociedad, donde la dignidad de la vida de la persona humana se ha perdido en favor del utilitarismo con las biopolíticas estatales, soslayando el primero de los derechos humanos: el derecho a la vida, dando cabida a la "pena de muerte prenatal". Este es lo que se observa al analizar las legislaciones colombiana y española. A pesar de esta palmaria realidad en los principios de la bioética se constituyen los valores de una ética mínima para las sociedades con matices de multiculturalidad y pluralismo que hacen reflexionar al bioderecho, ante la dimensión e importancia de la vida.

"La opción de abortar no debe significar indiferencia respecto al valor de la vida en gestación, sino que la decisión de interrumpir voluntariamente lembarazo debe ser vista como una cuestión de gran importancia moral [...] la responsabilidad se fomenta de muchas maneras. Una de ellas es la educación sexual; otra el modo en que la administración, el sector sanitario y la sociedad en general interpretan la despenalización del aborto. [...] la educación sexual por su parte, no sólo ha de procurar una información correcta y adecuada a las personas que la reciben, sino que debe ser vista como formación integral de la personalidad, es decir, como formación en la responsabilidad hacia las relaciones sexuales y la reproducción. [...] Debe reconocerse, sin embargo, que por alta que sea la tasa de abortos, esta nunca será suficiente para despenalizar la interrupción del embarazo" (24).
Evitar la "pena de muerte prenatal" ante el aborto generalizado, es pues, una tarea pendiente de las Cortes Generales en España y del Congreso de Colombia, con los postulados de la dignidad humana que le asiste al nasciturus, haciendo acopio de Kant, como un fin en sí mismo y no como un medio, restituyéndosele su condición de ser humano desde el momento mismo de la concepción.

\section{Referencias}

1. Guerra, Yolanda M. Medicina y Derecho El Control de la Vida y La Muerte del Individuo, Desde La Norma. Revista: Prolegómenos. Derechos Y Valores 2012 Xv (29) ISSN 0121-182X páginas 67-77.

2. Zárate, Amparo, "El bioderecho como instrumento en la determinación de los límites a la libertad de investigación: especial referencia a la eugenesia positiva en genética humana”, Tesis Doctoral Universidad Complutense de Madrid. Diciembre de 2011.

3. Romeo, Carlos María., Aborto en Enciclopedia de Bioderecho y Bioética (Tomo 1, pp. 4-8). Granada. Editorial Comares. S.L.

4. Zárate Amparo, Implicaciones bioéticas y biojurídicas de la objeción de conciencia institucional con relación al aborto en el ordenamiento jurídico colombiano, en Prolegómenos: Derechos y Valores, revista de la Facultad de derecho de la UMNG, Vol. XIV-N 27, enero-junio, 2011.

5. Artículo Quinto del Decreto 4444 de 2006 Ministerio de la protección social de Colombia, políticas públicas 2006.

6. Hoyos, I. El aborto y los efectos del decreto anulado. Recuperado del sitio de internet de la Conferencia Episcopal de Colombia: http://www.cec.org.co/index.php?option=comcontent\&view=article\&id=1149:el-aborto-y-los-efectos-deldecreto-anulado\&Itemid=2122013.

7. Roa (2013), F.A.Q. Sobre los efectos de la nulidad del decreto 4444 sobre el aborto legal y seguro en Colombia. Recuperado de: http://genderjusticejournal.wordpress.com/2013/03/20/fa-q-sobre-los-efectos-de-la-nulidad-del-decreto-4444-sobreel-aborto-legal-y-seguro-en-colombia/

8. Koch E., Bravo M., Gatica S., Stecher JF., Aracena P., Valenzuela S., Ahlers I. Sobrestimación del aborto inducido en Colombia y otros países latinoamericanos. Ginecol Obstet Mex. 2012., 80(5), pp. 360-372.

9. Prada Biddlecom y Singh, Aborto inducido en Colombia: nuevas estimaciones y cambios de 1989 a 2008, Perspectivas Internacionales en Salud Sexual y Reproductiva, número especial de 2012.

10. En Colombia se realizarían cerca de cuatro millones de abortos al año, recuperado de: http://www.caracol. com.co/noticias/ entretenimiento/en-colombia-se-realizarian-cerca-de-cuatromillones-de-abortos-al-ano/20080 909/ nota/ 667873 .aspx 
11. Informe disponible en línea: http://www.measuredhs. com/ pubs/pdf/FR246/FR246.pdf

12. Serrano, José Miguel, El aborto, de la mano de la eugenesia, en Aceprensa 2010. Tribunal constitucional español, (1985) sentencia 11-04-1985, núm. 53/1985, recuperado del sitio de internet del BOE: http://www.boe.es/boe/dias/1985/05/18/ pdfs/T00010-00025.pdf.

13. Gabaldón. Aborto y jurisprudencia constitucional en Mujer y realidad del aborto, un enfoque multidisciplinar: Actas del I Congreso Internacional Multidisciplinar "Mujer y realidad del aborto", Cáceres, 8-10 de marzo de 2007, Ed. Manuel Lázaro Pulido, 2008, pp. 299-306.

14. Tribunal Constitucional de España 1985.

15. Art. 417 bis del Código Penal de 1973, redactado conforme a la LO9/1985, vigente según la Disposición Derogatoria Única 1.a) de la LO 10/1995 del Código Penal.

16. Agea, Ong. Recuperado del sitio de internet de la Ong Agea: 2013. http://www.agea.org.es/index.php/secciones/ bioéticay-ciencia/80--sp-539/773-juristas-cientificos-y-filosofos-coinciden-el-feto-es-un-ser-humano.
17. IPFE. Documento del Instituto de Política Familiar en: http:// www.ipfe.org/documentacion.htm. 2013.

18. Morin, C. Reportaje emitido por la televisión Danesa. Plataforma del caso Morin del Centro Jurídico Tomás Moro http:// www.casomorin.tomas-moro.org/home. 2006.

19. Ollero, M. El aborto y el Tribunal Constitucional, recuperado del sitio de internet: http://www.conoze.com/doc. php?doc=9519.

20. Pinto, M. Temas de derechos humanos, Ed. Del Puerto, Buenos Aires, 2da Edición, pp. 200. 2009.

21. Fondevila, M. Recensión de Fukuyama, F., La construcción del Estado. Hacia un nuevo orden mundial en el siglo XXI, 2009. pp. 152-153.

22. Serrano, R; Calderón, José M. El aborto, de la mano de la eugenesia 2010 .

23. Vega, A. Investigación: aborto y eugenesia. 2012. http:// tododependeinfo.wordpress.com/2012/05/05/manana-audio-del-programa-\%E2\%80\%9Cevidencias $\%$ E2\%80\%9Daborto-y-eugenesia/

24. Camps, V. Derecho a la procreación. En Enciclopedia de Bioderecho y Bioética (Tomo 1, pp. 7-8). 2011. 